\title{
Hands-on versus virtual: Reshaping the design classroom with blended learning
}

\author{
Katja Fleischmann \\ Griffith University, Gold Coast, Australia
}

\begin{abstract}
The heart of design studio teaching is traditionally linked to one-on-one teaching activities and to the exchange of feedback prompting many design educators to think it does not lend itself to online delivery. This study explored how design educators can translate the essence of design studio pedagogy into a blended learning environment. The four-year study involving $\mathrm{H}_{4}$ first-year undergraduate design students reports on the development, implementation, and iteration of a blended learning experience in an introductory design subject. The subject followed a flipped classroom model where video lectures, software tutorials, and additional readings were delivered online through a Learning Management System; practical face-to-face tutorials allowed students to work on their projects, present their work, and engage in the dialogical learning process. Student and design instructor feedback was collected to evaluate the changes and overall effectiveness of the design of the blended learning experience, which proved to be effective.
\end{abstract}

\section{Keywords}

Design education, blended learning, design studio, online design studio, technologyenhanced learning, flipped classroom

\section{Introduction}

Design encompasses a range of areas such as urban design, architecture, graphic and digital media design, and fashion and interior design. Despite their disciplinary

\section{Corresponding author:}

Katja Fleischmann, Queensland College of Art, Griffith University, Gold Coast, QLD 4215, Australia.

Email: k.fleischmann@griffith.edu.au 
differences, design educators in higher education programs apply similar learning and teaching strategies such as studio-based teaching commonly known as the design studio (Crowther, 2013; McCarthy and Almeida, 2002). The design studio is regarded as a unique physical space, a social environment, and a mode of teaching and learning (Crowther, 2013; Hart et al., 2011; Shreeve, 2011; STP, 2009). In a traditional design studio, students usually work in small groups of 10 20 students who interact and learn through dialog with their teacher and peers (Crowther, 2013; Shreeve et al., 2010; STP, 2009). Design students work on projects that have open-ended design briefs often without a single correct answer (Crowther, 2013). Design learning is therefore often based on one-on-one teaching activities and the exchange of feedback to guide students developing a response and their creative potential (Fleischmann, 2016; Mohammed, 2017; Shreeve and Batchelor, 2012).

Design students in this study were preparing to become graphic or media designers. Students learning these skills usually engage in branding design, information design, motion graphic design, and interactive media/interface design in their professional practice. Therefore, a typical first-year student project is the development of a brand which includes designing a logo and other identity elements such as a website for a fictional or real-world client. It is such practicebased project work which engages design students in experiential learning (Kolb, 1984) and learning by doing as described by Schön (1987) (which is based on direct interactions between student and mentor) that is seen as the main challenge to teaching design in an online or blended learning environment. During interactions with teachers, peers, and sometimes design professionals tacit knowledge is transmitted (Daniel and Fleischmann, 2014; Crowther, 2013; Lee, 2006; Mohammed, 2017) which some educators feel could be lost in an online or blended learning environment. Indeed, various researchers found that educators believe that design studio teaching is inextricably linked to face-to-face teaching and design education does not lend itself to be delivered fully online (e.g. Fleischmann, 2015; Mohammed, 2017; Saghafi et al., 2012). Because design teaching and learning is largely perceived as a face-to-face activity, design educators are overlooking more flexible learning opportunities that include an online component in a blended learning context.

Although augmenting the design studio with digital technology is not a new approach, particularly the Virtual Design Studio has been explored to some extent since the mid-1990s (e.g. Bradford, 1995; Kvan, 2001), blended learning (also sometimes called technology-enhanced or hybrid learning) has at this time not been fully explored in design education (Chou, 2018; Pektas, 2012). Pektas (2012: 693) even argues "the delivery modes in [design] studio teaching have not much evolved as a response to changing generations and developing technology." Similarly, Power and Kannara (2016: 7) found that technology-enhanced learning is "used significantly less in the creative arts [which includes design] than in humanities." 
Nevertheless, design educators have begun augmenting design learning with digital technology to create online or blending learning experiences. Blended learning incorporates both face-to-face classrooms contact either in lectures or studio tutorials and the delivery of some parts of the content or activities online. The online part of blended subjects often incorporates an online platform such as a Learning Management System (LMS) as a resource center. Online lectures, discussion forums, file and video sharing are often part of blended learning experiences and can be augmented by social media tools such as Facebook to incorporate professional feedback or facilitate collaboration among students.

Following a global trend to offer more flexible study options for students in higher education, which means giving students a certain level of control over pace, time, and place of their learning, the author's university (at the time of this research) developed an institution-wide curriculum vision aligned to a blended learning approach. Enabling academics to implement the vision, the institution provided guiding documents which explained blended learning and its benefits. Blended learning is described by the institution as a "learning design that strategically, systematically and effectively integrates a range of face-to-face, online, mobile, distance, open, social and other technology enhanced learning across physical and virtual environments" (JCU, 2019). Flexible delivery options were presented as part of such a blended learning approach and is defined as "how the timing, pace, content, assessment and location (in both virtual and physical environments) of learning can be varied, personalised and chosen by the student to suit their needs, whilst still meeting the desired learning outcomes" (JCU, 2019).

To realize the vision, the author looked at the essence of design studio pedagogy and considered the challenges that might arise when developing a blended learning experience for design students. By doing so, the author followed Bates' (2005: 136) suggestion and explored "what is educationally advantageous in face-to-face teaching, and when face-to-face can be replaced with gain or without loss by online teaching." Hence this research explores "How can design educators use a blended learning environment to offer more flexible learning opportunities while keeping the essence of design studio pedagogy intact?"

This research details the development of a blended learning experience in a first-year design studio subject. A subject is described here as a semester-long specific class (Introduction to Media Design) and the summary of subjects are forming a specific course or degree program (Bachelor of Arts and Creative Media). The development and decision-making process was driven by reviewing existing research on blended learning in design education and previous work conducted by the author (Fleischmann, 2020). The newly developed blended learning subject was trialed twice while student responses suggested and informed a further subject re-design. Student and instructor feedback was collected in two subsequent trials to evaluate the changes and overall effectiveness of the design of the blended learning experience. The research presented spans four years. 


\section{The traditional design studio as pedagogy and its recent changes}

Learning to become a designer is based on a rich dialogue between design educators/instructors and students, peer communication, cooperative learning and sharing of information and ideas (Hart et al., 2011; Park, 2011; Shih et al., 2006). Studio critiques, where students present their work in progress and receive feedback from instructors and peers, provide a starting point for reflection which is anchored in Schön's (1983) concept of the "reflective practitioner" - a cycle of action and reflection to improve their practice (Ellmers, 2006; Schön, 1987). Although design studios are similar across the developed world (Crowther, 2013), the time spent in a studio varies greatly between institutions and design disciplines. However, students usually attend at least a one hour lecture per week and two to three hours studio time with supervising academic staff. Students also spend an additional three hours or more in the studio without academic staff (Crowther, 2013; STP, 2009). Studiobased teaching nowadays often takes place in computer labs which still support the creation of a social space where students can develop peer learning (Daniel and Fleischmann, 2014; Shreeve, 2011).

As funding diminishes, universities are looking for new ways to increase enrolment numbers and deliver programs more cost-effectively. Design courses, which are traditionally smaller, are not exempt from these economic realities. The move to economize is also putting pressure on the delivery of studio-based design subjects that require face-to-face contact with an instructor as mentor which is considered a luxury by some institutions (Filimowicz and Tzankova, 2017; Marshalsey and Sclater, 2018; Sims and Shreeve, 2012). Some universities have responded to these pressures by adapting a large lecture format with small breakout sessions featuring design labs or tutorials (Fleischmann, 2016; Daniel and Fleischmann, 2014; Filimowicz and Tzankova, 2017). Some design educators use digital technology to re-shape the traditional design studio to cope with larger classes. For example, Zeeng et al. (2009) worked with 320 creative arts students across three universities in their blended learning study; Schnabel and Ham (2012) worked with 178 architecture students; Withell et al. (2012) conducted a trial with 85 product design students in their blended learning class; and Fleischmann (2014) conducted a trial with 142 digital media design students.

Marshalsey and Sclater (2018: 96) see "far-reaching transformations from the original studio context" and observed that students are using digital technology such as laptops which makes "hot-desking" become more common and so the physical studio space becomes portable. According to various authors (e.g. Daniel and Fleischmann, 2014; Crowther, 2013; Marshalsey and Sclater, 2018: 92), design education "is now adapting the knowledge and approaches from within studio pedagogy ... to classroom-based learning" which leads to "conventional design studio facilities being reconfigured into blended studiobased classroom learning spaces (often generically termed as 'studio')." 


\section{Blended learning in design education}

Early attempts to augment the design studio with digital technology started in the mid-1990s (e.g. Bradford, 1995; Kvan, 2001; Maher and Simmoff, 1999) with researchers mostly reporting on challenges created by technology rather than how it can support a particular pedagogical approach specific to design education. "Blended learning" was not a concept that informed this early research work. More recently, design educators have started to embrace blended learning more intentionally. Although only a small number of research studies are available, some common objectives can be identified, which are to

- provide more flexibility for student learning as part of the design curriculum (e.g. Pektas, 2015);

- help students to become autonomous learners (e.g. Kocaturk, 2017);

- cope with larger-size design classes (e.g. Schnabel and Ham, 2012);

- connect studio classes across various institutions and countries (e.g. Zeeng et al., 2009); and to

- keep the design studio teaching relevant and in line with technological developments in the professional field (e.g. Masdéu and Fuses, 2017).

Research on blended learning in the design studio (although not always identified specifically as "blended learning") includes graphic design, product design, media design, architecture, fashion design, interior design, digital photography, advertising, digital media, construction and landscape architecture. These published studies explore ways to enhance design studio teaching using digital technology such as an LMS; online communication tools such as blogs and discussion boards; social media platforms like Facebook; and image sharing platforms such as Flickr and Pinterest. Research exploring blended learning in the context of a flipped classroom model for design education has also been published. In order to decide on the most appropriate/effective approach for the re-design of the firstyear design studio subject, each approach was reviewed and is briefly discussed in their application to design education.

\section{Learning Management Systems and cloud computing for blended learning in design education}

Some blended learning approaches incorporate an LMS such as Blackboard and Moodle as an online resource center where students can access assignments, readings, videos, etc. online. These LMSs also enable communication between the design teacher and students through online discussion forums. Students can also participate in online critiques, receive or give feedback, and submit their design work online for assessment. An early trial conducted by Nováková et al. (2010) used Moodle as a repository and collaborative teamwork platform in a design studio subject. The LMS was considered useful as an online repository but less 
so for sharing of files in real time which is a finding supported by Devetaković et al. (2011). Pektas and Gürel (2014) who augmented the design studio with the LMS Moodle and Facebook saw a natural migration of the design students' teamwork communication to Facebook. As an online repository, the LMS was considered useful and easy to use which confirmed earlier findings by Pektas and Demirkan (2011) - making it a technology to consider.

LMSs are now often available as cloud solutions which helped Pektas (2015) and Masdéu and Fuses (2017) to overcome time and physical space when connecting design studio students across countries or institutions. Kocaturk (2017) who used cloud-based Wiki sites to augment the studio argues that students had higher level of personal motivation, autonomy and student-led activities. Pektas (2015) also argues for the use of cloud-based solutions to provide flexibility and expansion to the traditional studio environment. Typical cloud-based solutions that are now commonly used in design practice include file-sharing services such as Dropbox and OneDrive and collaboration tools such as Slack or ConceptBoard. Pektas (2015: 257) clearly highlights the need to introduce design students to "the current trend in professional design practice" which is "characterized by self-organization of individuals into loose networks of peers to produce designs" using cloud computing tools.

\section{Social media tools for blended learning in design education}

The use of social media in the design studio has occupied a number of design researchers. Schnabel and Ham (2012) used the social networking site Facebook in a large-scale experiment involving 178 architectural design students, 8 tutors, and 1 course-coordinator. Studio sessions were conducted in face-to-face mode and Facebook was used to create a social network that would support communication between students in universities in Australia and Hong Kong. The researchers concluded that Facebook increased social engagement in the design studio, allowed better access to tutors, and encouraged many passive students to become active participants in the design process. However, the researchers also found that a small group of students dominated the online posts and some found Facebook as too informal, intrusive, and unprofessional. Schnabel and Ham (2012) concluded, in general, that social networks do not meet every learner's individual needs.

In a study involving 75 fourth-year graphic design students, Güler (2015) used Facebook to expand social interactions outside of the classroom. The researchers found that Facebook made communication easier, allowed students to access progress of their peers, and gave students the tools they needed to review and backtrack which contributed to their success. However, overall, Güler (2015: 194) also found that Facebook is "not designed for supporting educational processes and it does not provide learning tools."

Various researchers like Zeeng et al. (2009), Fleischmann (2014), and Filimowicz and Tzankova (2017) have incorporated the social media image sharing 
platform Flickr into design subjects. Filimowicz and Tzankova (2017) used Flickr and Dropbox to facilitate the change from teaching in a traditional design studio of 20 students to help about 100 digital photography students to create a final image portfolio based on feedback received from peers and instructors, an example of a technology-enhanced studio aiding reflective practice. A survey of the students found that the multi-level feedback system helped improve learning outcomes because of the sharing of feedback between student and staff. The study also found that some students did not participate enough in the feedback process while instructors had to teach students how to collaborate because many of them did not want to interact.

Fleischmann (2014) paired Flickr and Skype in a five-week project requiring collaboration between 142 first-year design students and 18 photography students at two geographically distant institutions in Australia. Social media was used to facilitate the communication and exchange between students of the two institutions. The LMS (Blackboard) provided the subject content for students. The design studio teaching was held face-to-face in groups of 40 students in the computer lab. Fleischmann (2014) reported that social media can enhance face-to-face learning, technology issues were minimal, and there was an increased interaction among students.

Zeeng et al. (2009) also coupled Flickr with Skype to test the efficacy of social media tools in a collaborative project among two universities in different parts of Australia and a university in the United States. The project involved 320 students in multiple programs including communication, design, fine and creative arts. The study explored the question whether distributed collaborative teaching partnerships can augment learning activities that improve student outcomes. Zeeng and her colleagues found that the Web 2.0 tools helped students to work independently yet share knowledge.

As can be observed from the above examples, social media tools are often used to connect students in different locations collaborating on one project when blended learning is used to augment the design studio. Its appropriateness to support learning in the collaborative design process is however questioned by various authors.

\section{The flipped classroom for blended learning in design education}

Some design educators have explored the flipped classroom model. The flipped classroom relies on the lecture content being delivered in online videos; students watch these lectures before coming to class to engage in learning tasks relating to the lectures during face-to-face tutorial or studio time. Various authors (e.g. Baytiyeh, 2017; Foldnes, 2016; Koo et al., 2016; Wanner and Palmer, 2016) see the benefits of the flipped classroom in that design students become more responsible for their learning and demonstrate increased engagement with the learning content and peer learning; in some cases, learning outcomes were improved using this model. Baytiyeh (2017), who used a flipped classroom in a web design subject, 
saw the main motivation in changing the outdated one-way and largely passive method of transmitting information. Hence Baytiyeh $(2017: 52,59)$ uses the flipped classroom for "moving information transfer out and moving information assimilation into the classroom" which was "highly effective in promoting student learning, interest, self-efficacy, and enjoyment"-thus also supporting findings from Chou (2018) who used a flipped classroom with online lectures, blogs, and discussion boards in architecture education.

Despite aforementioned positive outcomes, it needs to be highlighted that some researchers, for example, Wanner and Palmer (2016: 609), warn that the flipped classroom can become a "flopped classroom" because flipped learning depends on "self-regulated, highly self-motivated students who have the time management, organisational, analytical and critical thinking [skills]." Wanner and Palmer (2016: 608) argue that students become more "strategic in being successful in flipped classrooms without going through the flipped learning process" - a view that is supported by Abeysekera and Dawson (2015) who argue that today's students are more likely to be motivated extrinsically, hence are driven in their learning by what is assessed. Yick et al. (2019: 181) experienced low student engagement with design-specific video content in a first-year flipped fashion design classroom. However, they reasoned that first-year undergraduate students "tend to be less self-managed and self-regulated in their learning."

Looking at particular elements of the flipped classrooms in design education, Coyne et al. (2017) explored video use in depth. They see the benefits of delivering the lectures online in the variety of video formats that can be used which go beyond a voiced-over PowerPoint presentation and can also include interviews conducted with professionals. Coyne et al. (2017) used 10-15-min videos in their blended learning trial which they predicted would remain current for a couple of years. Creating shorter videos instead of one long one was also supported by findings from Yick et al. (2019: 186) who learned from their first-year fashion design students, that "most students demonstrated a short engagement duration of less than 10 minutes."

Design educators developed various strategies to keep students engaged throughout the semester by connecting online lecture videos with tutorial content. Coyne et al. (2017) provided a 20-min mini-lecture at the beginning of each face-toface class which summarized the video content students were required to watch at home. Baytiyeh (2017) gave a 10-min quiz and asked one student to summarize the content. Each approach resulted in a similar outcome with around half of the cohort watching the lectures - an outcome that would need to be improved when using such approaches.

\section{Subject development: Introduction to Media Design as blended learning experience}

Introduction to Media Design was the first design studio subject to be developed as a blended learning experience as part of the design major in the Bachelor of Arts 
and Creative Media. The subject runs for 13 weeks and introduces first semester students to the design process, engages them in a branding project, teaches them technical skills in professional design software, and gives students an overview of the history of Graphic Design and its role in business and society. The studio subject was previously taught face-to-face and required students to attend a weekly one-hour lecture and two-hour tutorial offered in a purpose-built computer lab (Daniel and Fleischmann, 2014). The LMS Blackboard was already being used since 2007 as a repository for study materials, assessment sheets, grades, and as communication tool to broadcast announcements.

As noted, it is important to pay close attention to which part of the blended learning experience is augmented by digital technology and hence delivered online. Findings from previous work (Fleischmann, 2020) in conjunction with insights gained from the literature review informed the decision-making process during the subject development. To briefly summarize previous findings which explored the design student attitudes toward online and blended learning at the author's institution, it was revealed that if students were given the choice between studying a design studio subject online or in a blended learning mode, they would prefer the flexibility of viewing lectures online but still wanted face-to-face design studio tutorials. Design students said, "that face-to-face interaction helps them learn ..." (Fleischmann, 2020). Students also prefer to ask questions directly; they enjoy the feedback from design instructors and peers; and they like being directly shown hands-on solutions to possible problems.

Given these insights and evaluating examples from the literature, the author decided to use the flipped classroom model for designing a blended learning experience. The flipped classroom model was selected because it supported greater flexibility for student learning, offered opportunities for students to take responsibility for their learning, and also facilitated peer learning - a characteristic of the design studio. The lectures were selected as one component to be delivered online. The two-hour studio tutorial in the computer lab would remain face-to-face and continued to be used by students to work on their real-world projects and directly interact with peers and educator, and receive real-time feedback. This decision was also supported by findings from Yick et al. (2019: 186) who argue that first-year students need more "hands-on guided learning." Although the author had previously used social media effectively in a first-year design subject (see Fleischmann, 2014) as had other design educators, social media were not used in this first-year design studio subject due to ambiguous views expressed about their use in an educational context.

Drawing on experiences and strategies employed by others using the flipped classroom model in design education (e.g. Coyne et al., 2017), it was evident that additional time is needed in the tutorial to discuss lecture content viewed by students prior to coming to class. To free up time, the author decided to augment the acquisition of software skills through digital technology, hence using online training tutorials. The decision was also supported by earlier findings which 
revealed that $85 \%$ of design students already watch online tutorials to learn new technical skills (Fleischmann, 2020).

Given the warning that some students take a strategic approach to learning and may not go through the flipped learning process (Abeysekera and Dawson, 2015; Wanner and Palmer, 2016), assessments had to be carefully considered when designing the subject. Design educators mostly use formative assessment (assessment for learning) to gauge how the student is progressing toward a learning goal (Fleischmann, 2016). For example, the studio critique is often used as a formative assessment where teacher and peer feedback function as a catalyst to improve students' creative output. Summative assessments (assessment of learning) such as an exam or test are usually not part of a project-based design studio subject. Student comprehension of lecture content is usually determined at the time the lecture is given, when discussing the content or during conversations about the hands-on project work. Given students were asked to self-manage their learning (hence watching lectures prior to coming to class) and low engagement with video content was reported by some researchers, an online multiple-choice test (assessing lower order cognition) was introduced as part of the flipped classroom. While at the start of trialing blended learning, the author placed high confidence in students watching the lectures voluntarily, the History of Graphic Design was seen as an area potentially skipped by some students. Hence the online test was focused on this area. The assessment was as follows: Online test, 20\%; Design project 1, 30\%; and Design project 2, $50 \%$.

The subject was developed by one design educator (the author) who also recorded the lecture content and was the Subject Coordinator (the person who manages the subject and teaching staff) during all trials. Three design instructors were responsible for teaching the face-to-face tutorials.

\section{Methodology: Investigating the blended learning experience, its effectiveness and re-design}

Because this research study does not align with a wholly quantitative or qualitative approach to design and methodology, it is framed by a pragmatic approach or "third way" of research (Armitage, 2007; Creswell, 2003; Morgan, 2007; Teddlie and Tashakkori, 2009). Applying a pragmatic research paradigm enabled the researcher to select methods that suit the real-world practice nature of the situation. Using a mixed methods approach, the perspectives of two stakeholder groups were obtained via questionnaires (students) and individual interviews (design instructors). The triangulation of data (Teddlie and Tashakkori, 2009), gathered from different sources, enabled comparisons to determine if findings were congruent and allowed a deeper understanding of the effectiveness of the blended learning experience.

The study presented is a four-year trial which involved 114 first-year undergraduate design students in the design major of the Bachelor of Arts and Creative 
Media and three design instructors. The first blended learning design of the subject Introduction to Media Design was run twice (Trial 1a and Trial 1b). At the end of each trial, students were asked to complete an online questionnaire which consisted of open- and closed-ended questions. Some aspects of the subject were re-designed based on the feedback provided in the first two trials. The re-designed blended learning subject was then run again twice (Trial 2a and Trial 2b). Students again gave feedback via an online questionnaire. The instructors' perspective was also explored after the first re-design of the subject and was captured through a semistructured interview lasting between 40 and $60 \mathrm{~min}$.

Throughout the process of data analysis, it was important to compare data within trials as well as across trials and stakeholder groups. Ultimately, these comparisons were needed to corroborate findings and also to discover possible contradictions in stakeholder perspectives or between quantitative and qualitative data that would require further investigations. Figure 1 illustrates the research process.

The research was driven by exploring the effectiveness of the online elements that augmented the traditional design studio: online lectures, commercial software tutorials, and the online test. The experienced benefits and challenges of the blended learning design studio and each augmented element were investigated from student and instructor perspectives. Additionally, to better contextualize design student feedback, they were asked about their prior blended and online learning experience.

For quantitative data obtained using online questionnaires, the web survey provider SurveyMonkey delivered basic statistical data, including the tally of response totals, percentages, and response counts. Qualitative data (responses from online questionnaires and interviews) were analyzed using the software NVivo - a qualitative data analysis program. Broad coding themes existed initially (e.g. "benefits" and "challenges"); however, the majority of themes were left to emerge during analysis.

Although 114 undergraduate design students provided feedback for this research, participant numbers in each trial represent a sample size congruent with smaller design classes: Trial $1 \mathrm{a}=43$ design students, Trial $1 \mathrm{~b}=37$ design students, Trial $2 \mathrm{a}=21$ design students, and Trial $2 \mathrm{~b}=18$ design students. To ensure that findings could be validated, each blended learning experience design was trialed twice (Trial $1 \mathrm{a} / \mathrm{b}$ and Trial $2 \mathrm{a} / \mathrm{b}$ ) so that the feedback from

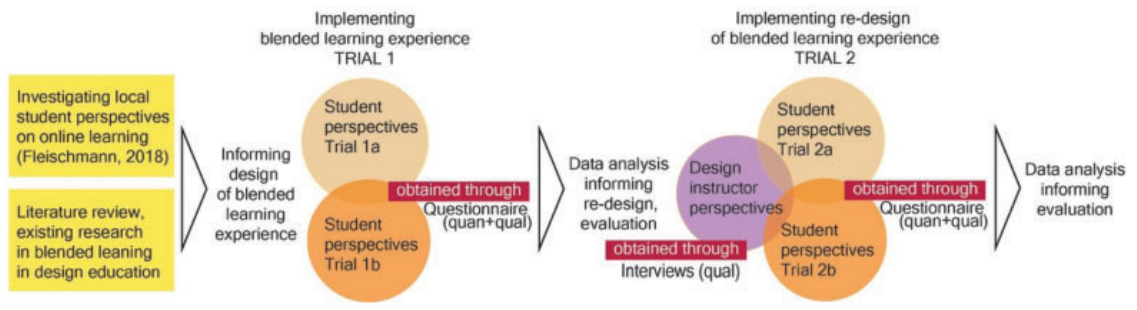

Figure I. Research process in exploring effectiveness of blended learning subject design. 
students could be compared within each trial set and across all trials. The feedback from three design instructors was also collected to allow for triangulation of data to ensure a more complete picture of the blended learning experience.

\section{Trial I: Subject design specifics}

This section provides some detailed insights into the specifics of the subject elements that were developed. Three elements of the design studio were augmented by digital technology and hence delivered online - the lectures, the design software training, and one assessment. The LMS Blackboard allowed students access to all course materials such as readings, grades, etc. from any place at any time with an Internet connection.

When considering how the face-to-face lectures are best translated into the online environment, various aspects such as types and length of educational videos were reviewed. That included screencasts, classroom/lecture recordings, talking head videos, interviews and presentations as they are seen in TED talks. In the end, the lecture material was recorded with the design educator talking directly to the camera (talking head style) and with a length of 8-15 min for each video, following Coyne et al.'s (2017) recommendation (see Figure 2 for examples). This style of presentation was also experienced as most engaging by the author when explored first hand by viewing Massive Open Online classes available on the edX platform.

The retention of information with many learners is higher when the content is seen and heard simultaneously. Therefore, to support information retention and potentially increase student engagement with video content, the decision was made to enhance the recordings through motion graphic design. A post-production team added graphic elements to the videos, such as summarizing lists, images, and animations (see Figure 3 for an example).

Industry professionals are part of many design studio classes. They can be involved by either giving guest lectures providing students with insights into professional practice, judge or provide feedback on student design projects, or they often teach as instructors (Fleischmann, 2012; Shreeve et al., 2010). In the Introduction to Media Design subject, industry professionals usually gave two guest lectures to excite students about their future careers. A way to best recreate the experience was sought through recording conversations/interviews with design professionals. All videos were hosted on a YouTube channel and made available

\begin{tabular}{|l|r|}
\hline NM1400: Lecture 2.1 - The Client Briefing & $7: 15 \mathrm{~min}$ \\
\hline NM1400: Lecture 2.2 - Corporate Identity & $10: 37 \mathrm{~min}$ \\
\hline NM1400: Lecture 2.3 - The Style Guide & $8: 51 \mathrm{~min}$ \\
\hline
\end{tabular}

Figure 2. Samples showing video length of lecture videos delivered online in week 2. 

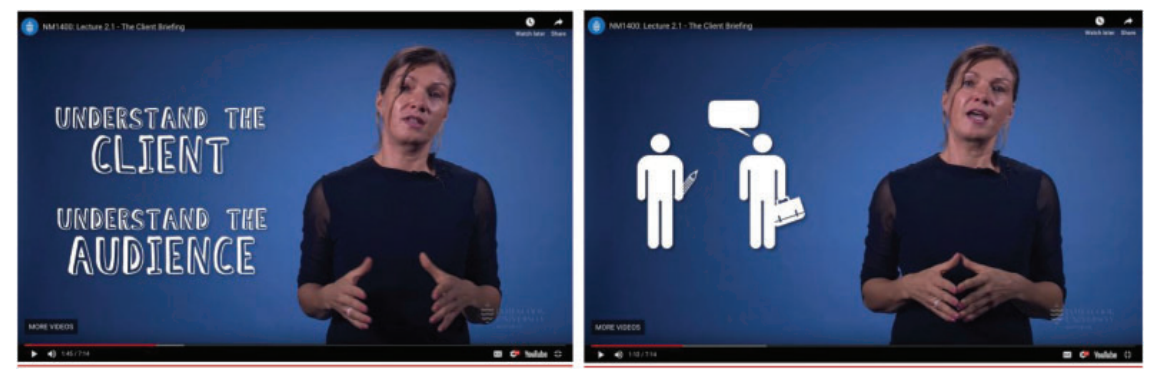

Figure 3. Sample screens from online lectures.

through the LMS Blackboard, together with all other subject materials. This configuration was chosen to provide flexible learning opportunities allowing students to access the learning materials at their convenience. Hosting the videos on the YouTube channel had the advantage that the researcher could monitor the number of views of each video.

Selecting an online service for software training tutorials for students - in this case, Adobe Illustrator-was mainly driven by the institution's existing subscription to Lynda.com (now LinkedIn Learning) which provided students with free access. Lynda.com is an online learning platform which offers video courses taught by industry experts in software, creative, and business skills.

The online multiple-choice test which was used to motivate students to view lecture videos on the history of Graphic Design (assessing lower order cognition) was created using the available test builder in the LMS Blackboard.

Although the institution had not provided workload or budget allocation, the head of the academic group provided each academic with $100 \mathrm{~h}$ workload for the development of the blended learning experience for one subject - that included the preparation, writing of scripts, testing, recording and revisions of the lecture videos.

\section{Trial I findings: Subject evaluation of the blended learning experience in the first-year design subject}

\section{Trial I: Design student perspectives on the blended learning experience}

When design students were asked whether they liked the blended learning experience (yes/no), the majority of students, 79\% (34 students) in Trial 1a and 70\% (26 students) in Trial 1b, liked the blended learning experience. When asked about their previous experience with blended and online learning in Trial 1a, 32\% of students had experienced blended or online learning prior to studying the subject Introduction to Media Design and even fewer, $29 \%$ of students in Trial 1b. Students 
who liked the blended learning experience commented to a large extent on the advantages of online lectures but also saw other benefits:

- Videos can be watched at any time.

- Videos can be watched more than once.

- Videos can be stopped to have a break, adjust to own learning pace and for note taking.

- Blended learning provides greater flexibility for learning and organizing busy life schedules.

- Less travel time to university.

Design student feedback highlights that they see the increased flexibility (timing and pace of learning; when to learn) as a major benefit.

Around one-third of design students did not like the blended learning experience in the first two trials: in Trial 1a $21 \%$ (9 students); in Trial 1 b 30\% (11 students). They gave the following reasons:

- Students cannot ask questions right away when watching lectures.

- Students learn better when interacting with people.

- Students are more motivated to attend lectures when they are face-to-face.

The following comment is a representative example of the challenges a minority of students cited: "It was ok but I would prefer face-to face-lectures as I learn better that way with other people, I get less distracted and I am more focused."

\section{Trial I: Design student perspectives on online design lectures}

When design students were questioned directly about their experience with viewing online lectures, the cohort was roughly divided in half in both trials (see Table 1).

Table 1 highlights that while there is a significant number of students being satisfied with their experience, there is a similar amount of design students being undecided about their experience, sometimes liking it and sometimes not. However, it is significant that only very few students expressed the preference for face-to-face lectures.

Table I. Trial I Design students' experience with viewing lectures online.

\begin{tabular}{lll}
\hline $\begin{array}{l}\text { How did you like that you could access/view } \\
\text { the lectures online? }\end{array}$ & $\begin{array}{l}\text { Trail Ia } \\
\% \text { (number } \\
\text { of students) }\end{array}$ & $\begin{array}{l}\text { Trial Ib } \\
\% \text { (number } \\
\text { of students) }\end{array}$ \\
\hline $\begin{array}{l}\text { I think it was good } \\
\text { I am still undecided, sometimes I liked it and sometimes }\end{array}$ & $56(24)$ & $43($ I6) \\
$\begin{array}{l}\text { I did not } \\
\text { I would have preferred face-to-face teaching in the lectures }\end{array}$ & $2(I)$ & $49(18)$ \\
Total number of students & 43 & $8(3)$ \\
\hline
\end{tabular}


Learning how to become proficient in the use of design software was also offered as an online component of the subject. The large majority of design students commented positively on the commercial software tutorials and found them helpful $(93 \%$ in Trial $1 \mathrm{a} ; 79 \%$ in Trial 1b). A general student attitude is reflected in this comment: The "Lynda videos are easy and interesting to watch and follow along within my own time. The videos were easy to understand, high quality, and delivered information in a way that was engaging."

Students not being satisfied with their software training using online tutorials mostly questioned the appropriateness of engaging in self-directed learning and preferred to be shown directly and hands-on by the instructor at the university as the following comment illustrates: "I did like the Lynda videos but ... it's a little silly and a waste of time for me, as it just seems like I could have learnt Media Design at home."

\section{Additional evidence driving the re-design of the blended learning experience}

Although the majority of design students "liked" the blended learning experience in the first two trials, the author decided to look at another source to gauge the engagement of students with the online lecture content. YouTube provides the opportunity to see the overall view count of videos, and hence the researcher compared the enrolment numbers in each class with the number of times each online video was viewed. Although the view count cannot be attributed to individual students (a student could have watched a video more than once while another student left out a video), the view count is used as an estimate of popularity. In the first week the viewing times were above $100 \%$; for example, in Trial 1a, Lecture 1.1 was viewed $137 \%$ when compared to the number of students enrolled in the class. This suggests that some students viewed the video multiple times. However, by week 6 the viewing count had dropped to $52 \%$ for Lecture 6.1 and to just $12 \%$ for videos in week 12 . This dramatic drop was supported by survey comments such as "I did not watch many videos" and "I fell behind watching the lectures...."

An easy assumption could be made that the videos were not engaging enough; however, only one student in Trial $1 \mathrm{a}$ and two students in Trial $1 \mathrm{~b}$ called the videos "boring," suggesting that it was not the video content or the way they were produced that created the drop in viewership. On the opposite side, students provided positive feedback on the video production such as "Fun lecture videos presented with enthusiasm" and "as the lectures are only 10 minutes long per video, I could have breaks in between instead of sitting in a classroom for an hour listening to the lecturer speak." Nevertheless, there is a gap between student feedback and actual viewing times of the videos.

While the goal of providing more flexible learning opportunities through a blended learning approach has already been achieved in Trial 1, the dramatic drop in recorded lecture viewership while the semester progressed required re-considering the original blended learning design of the subject. Trial 2 was 
therefore about attempting to ameliorate this problem while retaining the flexibility that had already been achieved.

\section{Trial 2: Re-design: Subject design specifics}

In order to motivate students to learn, hence to watch the online lectures and to further stimulate students' self-managed learning, two strategies were used:

Firstly, instructors were asked to link the online lectures more directly to tutorial content. The three instructors involved in teaching the subject explained their approach as follows:

Instructor 1

During the tutorial I always try to refer to the lectures and pick up on some aspects of the online lectures so that students could relate to them. I see the tutorial as the bridge between the lectures and the assignment.

\section{Instructor 2}

I put aside time ... about 15 to 20 minutes so that students could talk to each other and with me. It was like a larger sort of discussion group.

Instructor 3

It was challenging to teach content that built on the video lectures, but I gave them a mini-lecture based on the content in the beginning of the tutorial and students could ask questions.

Secondly, given that online tests are, despite criticism, determined valuable "to assess twenty-first century learning, particularly but not exclusively in the foundational knowledge domain" (Boitshwarelo et al., 2017: 14), a second online multiple-choice test that specifically evaluated the learning from week 1-6 was introduced. The decision was further supported by findings that running more regular low stake online tests can "prevent students from falling behind" (Boitshwarelo et al., 2017: 11) and hence can motivate students to learn. Students who take a more strategic approach to learning would potentially also be more motivated to engage with the video learning content.

In combination, the two strategies were designed to engage more students in the flipped learning process.

\section{Trial 2 findings: Subject evaluation of the blended learning experience after the re-design}

\section{Trial 2: Design student perspectives on the blended learning experience}

When design students were asked in Trial 2 whether they liked the blended learning experience (yes/no), Trials $2 \mathrm{a}$ and Trial $2 \mathrm{~b}$ showed a better result after the re-design 
when compared to feedback in Trial 1: 90\% (19 students) in Trail 2a and 89\% (16 students) in Trial $2 \mathrm{~b}$ liked the blended learning experience in the subject. The same benefits as in Trial 1 such as being able to watch videos at any time were expressed.

Only two students in each trial did not like the blended learning experience $(10 \%$ in Trial $2 \mathrm{a}$ and $11 \%$ in Trial $2 \mathrm{~b})$. The positive change could be attributed to the re-design of the blended subject but also to a larger number of students already being familiar with online and blended learning approaches: $43 \%$ in Trial $2 \mathrm{a}$ and $39 \%$ in Trial $2 \mathrm{~b}$.

\section{Trial 2: Design student perspectives on online design lectures}

When design students were questioned directly about being able to watch the lectures online in Trial 2, an improvement compared to Trial 1 is noticeable. There is a positive shift in students' attitudes toward viewing lecture content online - an increase of $16 \%$ in Trial $2 \mathrm{a}$ and $20 \%$ in Trial $2 \mathrm{~b}$. While there are still some students undecided about their experience, no students selected the preference for face-to-face lectures in Trial 2a and Trial 2b (Table 2).

Similar to Trials $1 \mathrm{a} / 1 \mathrm{~b}$, students commented positively on the use of commercial software tutorials (Lynda.com) to acquire the necessary software skills and found them helpful: $86 \%$ in Trial $2 \mathrm{a}$ and $94 \%$ in Trial $2 \mathrm{~b}$.

As part of the re-design of the subject, design instructors developed strategies that better linked the online lecture content to the weekly tutorial content. Students appreciated instructor efforts as expressed by the following student comment: "I loved how both lectures and tutorials matched up each week. It created an easy flow, which made learning new things a lot better."

\section{Motivating students to learn?: Introducing a second online test}

After adding a second online test and linking lecture content more directly to tutorials, an increase in viewing times of online lectures is visible. Table 3 shows the viewing times for two exemplary online lectures in weeks 1,6 , and 12 from the

Table 2. Trial 2 Design students' experience with viewing lectures online.

\begin{tabular}{lll}
\hline $\begin{array}{l}\text { How did you like that you could access/ } \\
\text { view the lectures online? }\end{array}$ & $\begin{array}{l}\text { Trial 2a } \\
\text { (after re-design) } \\
\% \text { (number of students) }\end{array}$ & $\begin{array}{l}\text { Trial 2b } \\
\text { (after re-design) } \\
\% \text { (number of students) }\end{array}$ \\
\hline $\begin{array}{l}\text { I think it was good } \\
\text { I am still undecided, sometimes I liked it } \\
\text { and sometimes I did not }\end{array}$ & $\begin{array}{l}72(15) \\
28(6)\end{array}$ & $\begin{array}{l}61(1 \mathrm{I}) \\
39(7)\end{array}$ \\
$\begin{array}{l}\text { I would have preferred face-to-face } \\
\text { teaching in the lectures }\end{array}$ & $0.00(0)$ & $0.00(0)$ \\
\begin{tabular}{l} 
Total number of students \\
\hline
\end{tabular} & 21 & 18 \\
\hline
\end{tabular}




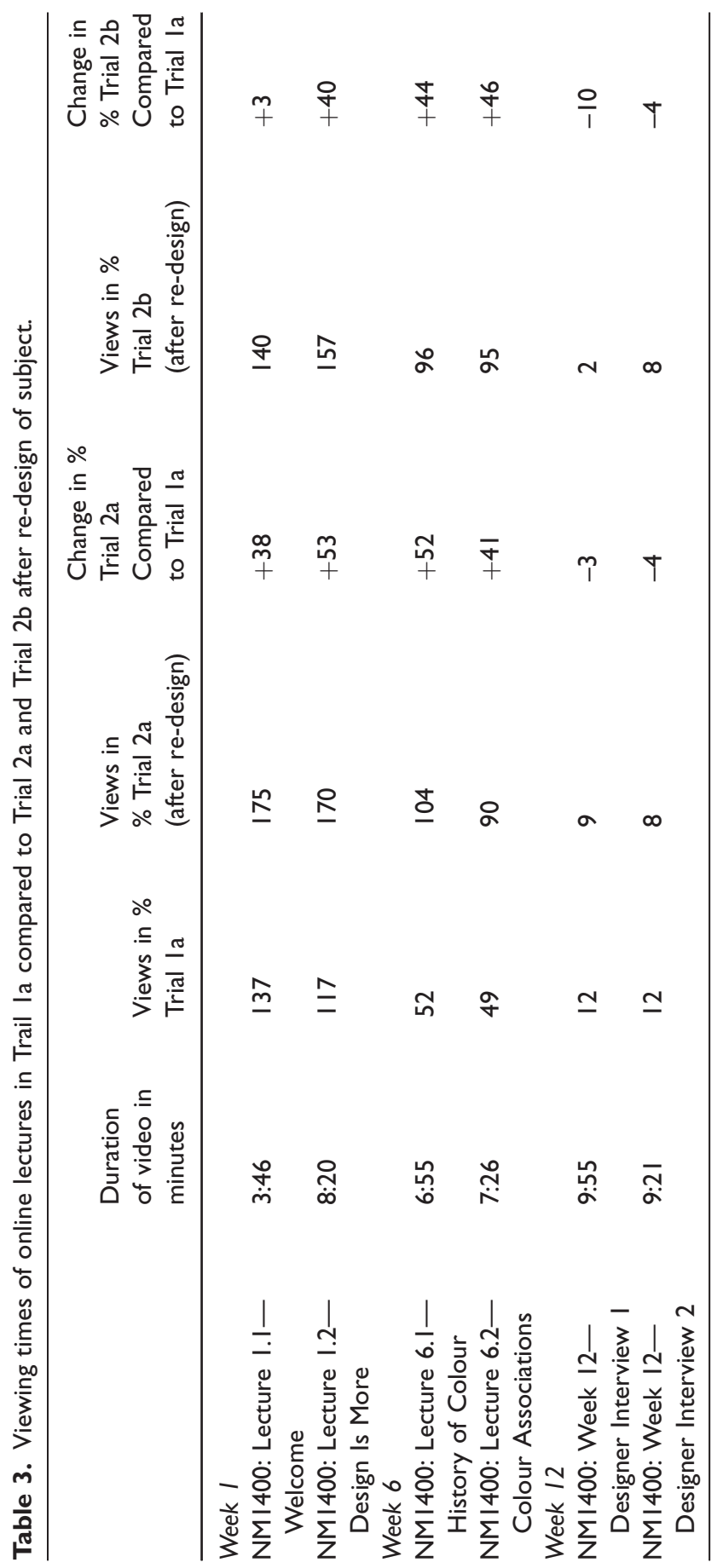


first Trial $1 \mathrm{a}$ and after the re-design in Trials $2 \mathrm{a} / 2 \mathrm{~b}$ - the change in viewing times is shown in percentages.

Table 3 clearly illustrates that the introduction of a second online test that covered weeks 1-6 motivated students to watch the online lectures. The viewing times of the videos in Trail $2 \mathrm{a}$ and $2 \mathrm{~b}$ increased significantly after the second test was introduced.

When design students were asked whether the online tests motivated them to watch the lectures, the feedback showed that $67 \%$ of students in Trial 2 a and $82 \%$ in Trial $2 \mathrm{~b}$ stated that this was the case. The remaining students stated that they would have watched the lectures without having the test.

However, an overall decrease in the number of times the online lectures were viewed from week 1 to week 6 is still noticeable in Trials $2 a / b$. The view count shows that not all students have watched the lectures in week 6 . In week 12 very low video viewing rates across all trials are recorded. Week 12 videos feature the interviews with design professionals with content being not part of any multiplechoice test.

\section{Reflection Trials I and 2: Design instructor perspectives on the blended learning experience}

All three design instructors had taught Introduction to Media Design face-to-face before teaching the subject in a blended learning mode. The instructors saw the blended learning approach as beneficial to varying degrees which was expressed as follows: "I am seeing more advantages"; and "The concept is really good"; and "There are pros and cons."

The instructor who critiqued online lectures said he missed student direct responses:

I prefer delivering lectures face-to-face because I like having that interaction with the students and I can see puzzled looks and respond more immediately. That's one benefit of delivering more formal lectures. It's that you can address any shortfalls in that information retention quite quickly. It's hard to say now with the blended mode.

Student comprehension of video lectures was also raised by another instructor who noted,

it was difficult sometimes when I wanted to address a question, I was never sure if students didn't understand that concept because they just didn't watch the lecture or if they didn't understand it because they just need a tiny bit more support.

The same instructor also commented favorably about the flexibility of online lectures, "with students being able to pre-watch key concepts and take that on board and then coming to the class and get down to the practical sides that concept 
is really strong." She also commented on the inherent limitations of face-to-face lectures: "It's hard to actually know if students did learn more when attending face-to-face lectures... you can have a full lecture theatre and a student can be sitting just there without comprehension ... attendance does not necessarily equal learning."

The third instructor mentioned that it seemed that mix of online and faceto-face teaching catered for different learning styles of students and that blended learning provided flexibility for most.

The main challenge all design instructors expressed was the struggle some students encountered with self-directed learning. Two instructors commented that some of the students did not comprehend well that they were responsible for their own learning and that "learning less," for example by not watching online lectures, may inhibit their overall progression in their studies and later professional development. The three design instructors agreed that the additional test motivated students to learn and watch more lectures. One instructor stated: "It is a better way of doing the tests. Splitting content in digestible chunks that is a bit less pressure for first year students and helped them to watch the lectures."

When instructors were asked to compare the quality of the creative work from face-to-face to the blended learning design, all instructors noted no difference between the works produced.

\section{Discussion}

The transformation of the first-year design studio subject from a fully face-to-face to a blended learning experience using a flipped classroom model worked well for the majority of design students who liked its flexibility. Students especially appreciated the convenience of watching online video lectures, which allowed them to review materials as often as deemed helpful and learn at their own pace. This provided design students with greater flexibility when and how to learn which was the aim of the author's institution when introducing blended learning as an institution-wide vision.

First-year design students had to take greater responsibility for their learning which was only partially successful in the first trials. To achieve that goal, the majority of design students had to develop the ability to self-manage their learning as argued by various authors as being a benefit of the flipped classroom (e.g. Baytiyeh, 2017; Koo et al., 2016) and that required a re-design of the initial blended subject. While the feedback from design students in the first two trials showed a high number of students liked the blended learning experience (79\% Trial 1a and $70 \%$ in Trial $1 \mathrm{~b}$ ), the research also showed that there was a significant decrease in the number of students watching the online lectures as weeks progressed in the semester. These findings confirm experiences made by others trialing the flipped design studio (e.g. Baytiyeh, 2017; Yick et al., 2019). By week 6, fewer than half of the design students watched the video lectures during the first two trials. Some 
students mentioned the lack of asking questions right away when watching the lectures as a challenge to their learning. The low viewership points to design students not going through the flipped learning process as was already identified by Wanner and Palmer (2016) as potential challenge when using this approach.

The two strategies trialed to overcome the challenge aiming to engage more students in the flipped learning process worked well. The mini-lectures which linked the online content more directly to the project work in the tutorials and provided direct opportunities for students to ask questions relating to the lecture content, led to a dramatic increase in viewing numbers of the online lectures. The introduction of a second online test also contributed to this increase. The majority of students and design instructors agreed that the tests motivated students to watch the lectures and learn. Overall, the feedback from design students after introducing these new strategies was very positive with even more students stating that they liked the blended learning experience; it increased to $90 \%$ of students in Trial 2 a and $89 \%$ in Trial $2 \mathrm{~b}$ with only two students in each trial being undecided about the experience and one student expressing a preference for face-to-face lectures.

These findings confirm what Abeysekera and Dawson (2015) and also Wanner and Palmer (2016) argue, that students become more strategic in their learning and focus on what is assessed. The very low viewing numbers of videos that were not included in the tests (e.g. interviews with industry professionals) support this argument. The feedback from design students revealed that it was not the style or length of the videos that kept students from viewing the lectures - on the contrary, students found them energetic and fun. The time invested by the educator and post-production team to create engaging videos that reach out to students with different learning styles paid off. Using more but shorter videos, as for example Coyne et al. (2017) suggested, was effective as commented on by students.

The feedback from students on the effectiveness of providing software learning in the form of online tutorials was very positive throughout all trials which confirmed previous findings from the author (Fleischmann, 2018) in that students are confident in self-manage learning technical skills outside the design studio. This approach was successful in saving time in studio tutorials to discuss the lecture content viewed by students prior to coming to class - which is a basic premise of the flipped classroom and helps increase engagement (Coyne et al., 2017; Wanner and Palmer, 2016).

Even the earliest experiments highlight the effectiveness of using LMSs to augment the design studio (e.g. Pektas and Demirkan, 2011). All content and communication were managed through an LMS in this study which is deemed necessary and was effective as central online repository to give students access to the subject learning materials regardless of time/location.

Design instructors generally supported the blended learning design model. However, two of the design instructors felt it challenging to identify students who had watched the lectures as required before the tutorial. Both instructors said they were missing the facial cues of students that would indicate they did not understand concepts presented in a face-to-face lecture - a point also made by Güler (2015). 
An important point not explored in other studies is whether or not the quality of the creative work produced by design students is influenced by the mode of delivery of a subject. Given that there is a strong argument from design educators to teach design face-to-face (e.g. Fleischmann, 2015; Mohammed, 2017), when asked to provide feedback, all design instructors agreed that the quality of work produced had not changed in the blended learning experience.

\section{Conclusion and outlook}

Various approaches to augment design studio teaching with digital technology are beginning to gain more traction despite a wide belief that design is better taught and learned face-to-face. The heart of design studio pedagogy is traditionally based on dialogical learning which guides the process of "learning by doing" and facilitates the process of students becoming reflective practitioners. This study set out to explore the potential of blended learning to offer more flexible study options for design students without losing the essence of design studio teaching and learning. This four-year study followed a flipped classroom model applied at a first-year undergraduate design studio subject.

Design students and instructors feedback suggests that this was an effective approach where the online components (lectures, software training, repository) enhanced the student learning experience in that students had greater control over pace, time, and place of their learning and less travel to and from the university was required. Helping students to better manage self-directed learning required the introduction of summative assessments (online tests) to motivate students to learn. Design instructors reported that the creative work produced was similar in quality when compared to work created in the fully face-to-face taught design studio.

This blended learning approach could be trialed in design programs at other institutions. The next iteration of this flipped design studio subject would continue to use

- talking head lecture videos enhanced through motion graphic design of around 10 min or less in length;

- software training tutorials to help design students acquire necessary technical skills in their own time and outside the design studio;

- summative assessment to motivate students to engage with online lecture content;

- mini lectures and discussions at the beginning of each studio tutorial to link the online content more directly to the face-to-face activities.

In addition, the following changes are suggested for the next iteration of the subject to further enhance the blended learning experience:

- Use a non-assessed online knowledge check at the start of each tutorial to additionally help overcome the challenge of some students not watching the lectures before coming to class. 
- Design industry professionals will be invited back into the studio to directly interact with students instead of relying on recorded interviews to inspire students for their future profession.

- Introduce a cloud-based collaboration tool (if teamwork occurs) such as ConceptBoard to extend the project-based learning opportunities beyond the design studio (Fleischmann, 2018) and to also introduce design students to the latest technology-enhanced work practices in the professional field (as suggested by Pektas, 2015; Masdéu and Fuses, 2017).

Given future departmental support at the author's institution, reshaping the design classroom using blended learning will be continued with further research informing the development of other design studio subjects in the degree. Although design teaching and learning is largely perceived as a face-to-face activity, design programs can provide flexible learning opportunities by including an online component in a blended learning context. This work is seen as a step toward paving the way for a fully online design program.

\section{Declaration of conflicting interests}

The author(s) declared no potential conflicts of interest with respect to the research, authorship, and/or publication of this article.

\section{Funding}

The author(s) received no financial support for the research, authorship, and/or publication of this article.

\section{ORCID iD}

Katja Fleischmann (D) https://orcid.org/0000-0002-0246-260X

\section{References}

Abeysekera L and Dawson P (2015) Motivation and cognitive load in the flipped classroom: Definition, rationale and a call for research. Higher Education Research \& Development 34(1): $1-14$.

Armitage A (2007) Mutual research designs: Redefining mixed methods research design. In: Remenyi D (ed.) British Educational Research Association Annual Conference. London, UK: Institute of Education, pp.1-10.

Bates T (2005) Technology, E-Learning and Distance Education. London: Taylor \& Francis Ltd.

Baytiyeh H (2017) The flipped classroom model: When technology enhances professional skills. International Journal of Information and Learning Technology 34(1): 51-62.

Bradford J (1995) Critical reflections I. In: Wojtowicz J (ed.) Virtual Design Studio. Hong Kong: Hong Kong University Press, pp.31-32.

Boitshwarelo B, Reedy AK and Billany T (2017) Envisioning the use of online tests in assessing twenty-first century learning: A literature review. Research and Practice in Technology Enhanced Learning 12(16): 1-16. 
Chou R-J (2018) Going out into the field: An experience of the landscape architecture studio incorporating service-learning and participatory design in Taiwan. Landscape Research 43(6): 784-797.

Coyne RD, Lee J and Petrova D (2017) Re-visiting the flipped classroom in a design context. Journal of Learning Design 10(2): 1-13.

Creswell JW (2003) Research Design: Qualitative, Quantitative, and Mixed Methods Approaches. Thousand Oaks: Sage.

Crowther P (2013) Understanding the signature pedagogy of the design studio and the opportunities for its technological enhancement. Journal of Learning Design 6(3): 18-28.

Daniel R and Fleischmann K (2014) Designing a learning space for creativity and collaboration: from studio to computer lab in design education. In: Nygaard C, Branch $\mathrm{J}$, Scott-Webber L, et al. (ed) Learning Spaces in Higher Education. Oxford: Libri Publishing, pp. $45-58$

Devetaković M, Arsić P, Nikolić I, et al. (2011) INTEGRATION OF E-LEARNING CONCEPTS IN URBAN DESIGN STUDIO: The case of a virtual learning environment supporting a specific educational mode. In: $Y U$ Info Conference, Kopaonik, Serbia, 6-9 March 2011, pp. 1-6.

Ellmers G (2006) Reflection and graphic design pedagogy: Developing a reflective framework to enhance learning in a graphic design tertiary environment. In: Baker S and Fereday $\mathrm{S}$ (eds) ACUADS 2006, Melbourne, Australia, 27-29 September 2006, pp. 1-10. Melbourne, Australia: Monash University.

Filimowicz MA and Tzankova VK (2017) Creative making, large lectures, and social media: Breaking with tradition in art and design education. Arts and Humanities in Higher Education 16(2): 156-172.

Fleischmann K. (2012) Industry-driven design education: how much should industry dictate pedagogy? In: Muratovski G (ed) AgIdeas Research: design for business. AgIdeas Press, Melbourne, pp. 76-79.

Fleischmann K (2014) Collaboration through Flickr \& Skype: can Web 2.0 technology substitute the traditional design studio in higher design education? Contemporary Educational Technology 5: 39-52.

Fleischmann K (2015) Democratisation Of Design And Design Learning - How Do We Educate The Next-Generation Designer. International Journal of Arts \& Sciences 8(6): 101-108.

Fleischmann K (2016) Peer Assessment: A Learning Opportunity for Students in the Creative Arts. In: Nygaard C, Branch J and Bartholomew P (eds) Assessing Learning in Higher Education. Oxford: Libri Publishing, pp. 45-58.

Fleischmann K (2018) Hype or help? Technology-enhanced learning in the design classroom: an experiment in online design collaboration. International Journal of Arts \& Sciences 11(1): 331-341.

Fleischmann K (2020) Online design education: Searching for a middle ground. Arts and Humanities in Higher Education 1-22. 2020; 19(1): 36-57.

Foldnes N (2016) The flipped classroom and cooperative learning: Evidence from a randomised experiment. Active Learning in Higher Education 17(1): 39-49.

Güler K (2015) Social media-based learning in the design studio: A comparative study. Computers \& Education 87: 192-203.

Hart J, Zamenopoulos T and Garner S (2011) The learningscape of a virtual design atelier. Compass: Journal of Learning and Teaching 2(3): 1-15. 
JCU (2019) Blended learning policy. Available at: www.jcu.edu.au/policy/learning-andteaching/blended-learning-policy (accessed 6 October 2019).

Kocaturk T (2017) A socio-cognitive approach to knowledge construction in design studio through blended learning. Journal of Problem-Based Learning in Higher Education 5(1): 1-21.

Kolb DA (1984) Experiential Learning: Experience as the Source of Learning and Development. New Jersey: Prentice-Hall.

Koo CL, Demps EL, Farris C, et al. (2016) Instructional design and assessment: Impact of flipped classroom design on student performance and perceptions in a pharmacotherapy course. American Journal of Pharmaceutical Education 80(2): 1-10.

Kvan T (2001) The pedagogy of virtual design studios. Automation in Construction 10(3): 345-353.

Lee N (2006) Design as a learning cycle: A conversational experience. Studies in learning. Evaluation Innovation and Development 3(2): 12-22.

McCarthy S and Almeida CMd. (2002) Self-Authored Graphic Design: A Strategy for Integrative Studies. Journal of Aesthetic Education 36: 103-116.

Maher M and Simmoff S (1999) Variations on the virtual design studio. In: Proceedings of Computer-Supported Collaborative Work in Design, pp. 1-13.

Marshalsey L and Sclater M (2018) Critical perspectives of technology-enhanced learning in relation to specialist Communication Design studio education within the UK and Australia. Research in Comparative and International Education 13(1): 92-116.

Masdéu M and Fuses J (2017) Reconceptualizing the design studio in architectural education: Distance learning and blended learning as transformation factors. International Journal of Architectural Research 11(2): 6-23.

Mohammed M (2017) Blended E-learning in the architectural design studio: An experimental model. International Journal of Parallel, Emergent and Distributed Systems 32(suppl 1): 73-81.

Morgan DL (2007) Paradigms lost and pragmatism regained: Methodological implications of combining qualitative and quantitative methods. Journal of Mixed Methods Research 1(1): 48-76.

Nováková K, Achten H and Matějovská D (2010) A design studio pedagogy for experiments in collaborative design. In: Future Cities, 28th eCAADe Conference Proceedings, Zurich, Switzerland, 15-18 September 2010, pp. 73-79. Zurich: ETH Zurich.

Park JY (2011) Design education online: Learning delivery and evaluation. International Journal of Art \& Design Education 30(2): 176-187.

Pektas ST (2012) The blended design studio: An appraisal of new delivery modes in design education. Procedia - Social and Behavioral Sciences 51(51): 692- 697.

Pektas ST (2015) The virtual design studio on the cloud: A blended and distributed approach for technology-mediated design education. Architectural Science Review 58(3): 255-265.

Pektas ST and Demirkan H (2011) Experiences with Moodle as a communication tool for design teamwork: A users' perspective. METU Journal of the Faculty of Architecture 28(2): 227-241.

Pektas ST and Gürel MO (2014) Blended learning in design education: An analysis of students' experiences within the disciplinary differences framework. Australasian Journal of Educational Technology 30(1): 31-44.

Power J and Kannara V (2016) Best-practice model for technology enhanced learning in the creative arts. Research in Learning Technology 24: 1-16. 
Saghafi MR, Franz J and Crowther P (2012) Perception of physical versus virtual design studio education. International Journal of Architectural Research: ArchNet-IJAR 6(1): 6-22.

Schnabel MA and Ham JJ (2012) Virtual design studio within a blended social network. Journal of Information Technology in Construction 17: 397-415.

Schön D (1983) The Reflective Practitioner: How Professionals Think in Action. New York: Basic books.

Schön D (1987) Educating the Reflective Practitioner. San Francisco: Jossey-Bass.

Shih S-G, Hu T-P and Chen C-N (2006) A game theory-based approach to the analysis of cooperative learning in design studios. Design Studies 27(6): 711-722.

Shreeve A (2011) The way we were? Signature pedagogies under threat. In: Bohemia E, Mozota BBd and Collina L (eds) Researching Design Education: 1st International Symposium for Design Education Researchers. Paris: CUMULUS ASSOCIATION// DRS SIG on Design Pedagogy, pp.112-125.

Shreeve A and Batchelor R (2012) Challenges to learning and teaching relations in higher education studio environments. BrightONLINE Student Literary Journal 18.

Shreeve A, Sims E and Trowler P (2010) 'A kind of exchange': Learning from art and design teaching. Higher Education Research \& Development 29(2): 125-138.

Sims E and Shreeve A (2012) Signature pedagogies in art and design. In: Gurung RAR, Chick NL, Haynie A, et al. (eds) Exploring More Signature Pedagogies: Approaches to Teaching Disciplinary Habits of Mind. Sterling: Stylus Publishing, pp.55-67.

STP (2009) Curriculum development in studio teaching. Volume One: STP Final Report.

Teddlie C and Tashakkori A (2009) Foundations of Mixed Methods Research: Integrating Qualitative and Quantitative Approaches in the Social and Behavioral Sciences. Los Angeles: SAGE.

Wanner T and Palmer E (2016) From flipped to flopped to flexible classrooms in higher education? - Critical reflections from Australia. ASCIKITE- Shaping the future of tertiary education, Adelaide, Australia, 27-30 November 2016, pp. 605-610.

Withell A, Cochrane T, Reay S, et al. (2012) Augmenting the design thinking studio. Ascilite 2012 Wellington, New Zealand, pp. 1-11.

Yick K-L, Yip J, Sau-Chuen A, et al. (2019) Effectiveness of blended learning in the first year of fashion education. International Journal of Fashion Design, Technology and Educational Technology \& Society 12(2): 178-188.

Zeeng L, Robbie D, Adams KM, et al. (2009) Where's my class? Using Web 2.0 for collaboration in a design environment. ASCILITE Auckland, New Zealand.

\section{Author biography}

Katja Fleischmann works as Associate Professor for Visual Communication Design at Griffith University, Queensland College of Art, Australia. She is an academic and researcher with extensive knowledge of global and national issues driving the design profession. Her research centres around two often interlinking areas, the role of design in social, public and economic innovation, and the future of design education. Katja has received national recognition from the Australian Learning and Teaching Council for her research-informed curriculum design work as design educator. 